\title{
Community-based hepatitis B screening: what works?
}

\author{
Monica C. Robotin · Jacob George
}

Received: 18 April 2014/ Accepted: 25 June 2014/Published online: 1 August 2014

(C) The Author(s) 2014. This article is published with open access at Springerlink.com

\begin{abstract}
Introduction Chronic hepatitis B (CHB) affects over 350 million people worldwide and can lead to life-threatening complications, including liver failure and hepatocellular cancer (HCC). Modern antiviral therapies could stem the rising tide of hepatitis B-related $\mathrm{HCC}$, provided that individuals and populations at risk can be reliably identified through hepatitis B screening and appropriately linked to care. Opportunistic disease screening cannot deliver population-level outcomes, given the large number of undiagnosed people, but they may be achievable through well-organized and targeted community-based screening interventions.

Material and methods This review summarizes the experience with community-based CHB screening programs published in the English-language literature over the last 30 years.

Results They include experiences from Taiwan, the USA, The Netherlands, New Zealand, and Australia. Despite great variability in program setting and design, successful programs shared common features, including effective community engagement incorporating the target population's cultural values and the ability to provide lowcost or free access to care, including antiviral treatment.

Conclusion While many questions still remain about the best funding mechanisms to ensure program sustainability
\end{abstract}

M. C. Robotin $(\bowtie)$

Cancer Council NSW and University of Sydney, Sydney, NSW, Australia

e-mail: monicar@nswcc.org.au

J. George

Storr Liver Unit, Westmead Millennium Institute and Westmead Hospital, University of Sydney, Westmead, Sydney, NSW, Australia and what the most effective strategies are to ensure program reach, linkage to care, and access to treatment, the evidence suggests scope for cautious optimism. A number of successful, large-scale initiatives in the USA, AsiaPacific, and Europe demonstrated the feasibility of community-based interventions in effectively screening large numbers of people with CHB. By providing an effective mechanism for community outreach, scaling up these interventions could deliver population-level outcomes in liver cancer prevention relevant for many countries with a large burden of disease.

Keywords Chronic hepatitis B - Hepatocellular cancer . Cancer screening and prevention . Community-based screening

\section{Background}

Chronic infection with hepatitis B virus represents a global public health challenge, given that approximately 350 million people are infected worldwide [1]. Approximately $95 \%$ of infected adults and older children can successfully clear the infection and become immune, but $90 \%$ of infected neonates and $25-50 \%$ of children infected in infancy become chronically infected [2]. Chronic hepatitis B (CHB) can remain asymptomatic for decades, but can lead to cirrhosis or hepatitis B-related liver cancer (hepatocellular cancer, or HCC) in approximately $25 \%$ of cases, explaining the 800,000 deaths/year attributable to the infection and its complications [3, 4]. The Global Burden of Disease study estimated that, of the 8.0 million lives lost to cancer in 2010, HCC was second only to lung cancer in terms of cancer deaths; half of these cases were hepatitis B related [4]. 
Over $80 \%$ of liver cancers occur in East Asia and SubSaharan Africa [5]; with increasing international migration, increasingly they are also HCC disease determinants in North America, Western Europe, and Australia, particularly among immigrant populations [6-9]. US Vietnamese males are 11 times more likely to develop HCC than nonHispanic Whites [10], and Australian males born in Vietnam are 13 times more likely to develop HCC than other Australians [8].

Currently available antiviral therapies have the potential to change the natural history of CHB, [11-14] given that screening and treating high-risk populations appear cost effective in studies from the USA [15], Canada [16], Australia [17], and The Netherlands [18]. This is predicated upon people being aware of their status and willing and able to access regular monitoring and treatment [19], not readily provided through opportunistic CHB screening. Current estimates suggest that two-thirds of Americans [19] and $40 \%$ of Australians living with CHB [20] are unaware they are infected; in the European Union this figure may be as high as $90 \%$ [21], with people undiagnosed (many of them migrants and underserved populations) destined to replicate the natural history of the disease [22].

Community-based screening could provide CHB screening in populations where limited English proficiency, lower socioeconomic and educational levels, lack of health insurance, and disease stigma preclude their ability to effectively navigate the health care system [23], with health care provider- and health system-related barriers posing additional challenges [24]. Hepatitis B vaccination is the mainstay of modern hepatitis B prevention. The implementation of universal vaccination has led to dramatic reductions in the overall hepatitis B disease burden, and as of July 2011, 179 countries reported inclusion of the hepatitis B vaccine in their national immunization schedules (up from 31 countries in 1992) [3]. However, vaccination is of no benefit to those already infected, who need to access medical care to mitigate disease outcomes [19]. Disease screening offers people already infected a gateway into care, which needs to remain open until the pool of existing infections is exhausted. While the approach to screening may vary, identifying those infected remains a priority in all countries which have sizable at-risk populations.

This systematic review examines the evidence around community-based hepatitis B screening, seeking to better understand the common factors of success and challenges.

\section{Methods}

We used Rein's definition of community-based hepatitis B screening programs, as those that "systematically offer
HBsAg testing to all members of a population group based on country of birth or participation in high-risk behaviour." This definition excludes "screening conducted by state and local public health departments, including screening performed by refugee health programs" [25].

Whitehead views community-based interventions (CBIs) as alternatives to "top-down" interventions designed to improve the health and/or socioeconomic status of the world's poor [26]. Based upon who initiates, drives, and carries out the intervention, he proposes seven types of community-based interventions, ranging from completely self-sufficient programs, driven and funded exclusively by the community (type 1) to those planned and implemented as equitable partnerships by the community in collaboration with an external change agent (type 7). The continuum includes interventions involving the recipient community to different degrees, from merely program recipients to active partners in program implementation, with the "ideal" CBI being a true partnership between technical experts and the communities they serve. The former contributes conceptual strength, comprehensive design, and rigorous implementation, while community endorsement and support increase the likelihood of program incorporation into its sociocultural context, strengthening sustainability and diffusion [26].

We graded the effectiveness of community engagement as "high" or "low" according to the programs' selfreported capacity to establish meaningful community partnerships.

Programs were also categorized using the four hepatitis B screening models described by Rein et al. [27] as:

1. Community clinic model (CCM), with screening integrated into routine primary care services; the screening decision is informed by risk factor review, with doctors providing counseling and testing referrals.

2. Community outreach model (COM), which involves screening in community settings (i.e., health fairs and community centers), with testing provided by phlebotomists and with volunteers providing logistical support at screening events.

3. Partnership and contract model (PCM), in which screening is contracted to general health screening companies (such as wellness campaigns targeting Asian employees).

4. Outreach and partnership model (OPM), which combines elements of COM and PCM; screening takes place in COM-type settings, with planning activities coordinated by a community organization with direct links to the target community.

We identified publications about community screening programs by searching PubMed and EMBASE for articles published in the English language from 1984 through 
Fig. 1 Diagrammatic representation of the search strategy and its outcomes

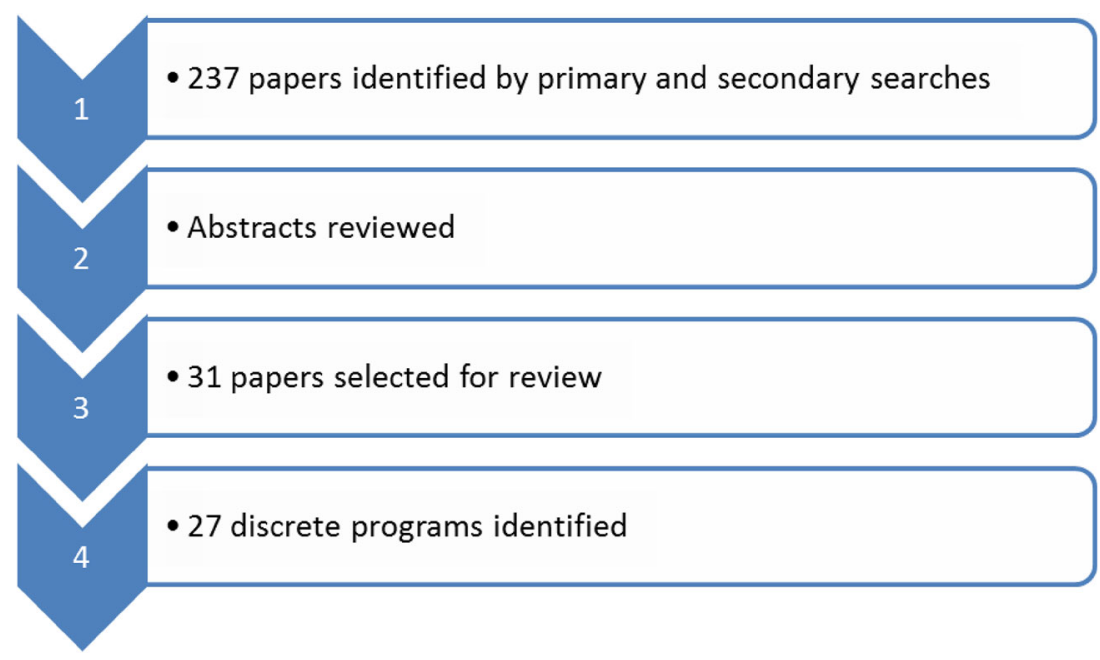

January 2014, using the terms "hepatitis B testing," "hepatitis B screening," combined with "community programs," "migrant screening," "CHB screening," "high risk," "population," and "population-based screening." Articles were entered into an Endnote (version X4, Thomson Reuters) database and identified abstracts reviewed. Full articles were retrieved if deemed relevant, with the list augmented with manual searches of reference lists. Where more than one publication described the same program, the paper providing the greatest level of detail was used as a key reference, with additional data from other publications included (and referenced) if they contributed salient information (i.e., updates on program outcomes). The overall search strategy is outlined in Fig. 1. Programs not providing details about how screening was conducted were excluded.

We extracted and tabulated the following information for each program:

1. Screening model employed and extent of community engagement

2. Program's target population

3. Program partners

4. Study type

5. Program components and services provided

6. Program outcomes

7. Program costs

\section{Results}

The search identified 237 papers; based upon the information provided in the abstracts, 206 papers were excluded, leaving 31 papers for review. As four of these reports described the same interventions (either different aspects or at different points in time), the final number of discrete programs was 27. Of these, 19 interventions were based in the USA, 4 in the Netherlands, 2 in New Zealand, and 1 each in Taiwan and Australia (Table 1).

Two US papers reported aggregate results of US-based community screening programs: one reported outcomes of a nationwide audit of community-based hepatitis B screening programs [25]; the other described four models of community-based screening [27], which we also used for consistency.

Screening model employed and estimated degree of community engagement

An OPM was employed by 13 programs. Some were large one-off initiatives (e.g., screening the entire population of Kawerau, New Zealand [28], the adult population of Taiwan [29], the Asian American and Pacific Islander migrants in Colorado, USA [30]), while others operated for a longer duration, such as programs in California (Hep B Free [31] and the Jade Ribbon Campaign in San Francisco [32] and a program run by the Asian Liver Center in Los Angeles [33]) and the BFreeNYC program in New York [34, 35]. Medium-sized OPM programs screened 1,000-2,000 participants: the Hepatitis B Initiative in Washington, DC [36], the Hepatitis Outreach Network (HONE) program in New York [37], and the Three for Life initiative in San Francisco [38]. Smaller OPM programs (screening $<1,000$ people) were run in conjunction with faith-based community organizations (i.e., Korean churches in New Jersey [39] and Montgomery County in Maryland [40]) and through health fairs in Michigan [41]. In addition to hepatitis B screening, OPM programs included specific outreach and educational activities, including hepatitis talks, distribution of printed materials, and web-based resources and effectively used ethnic media for publicity. 


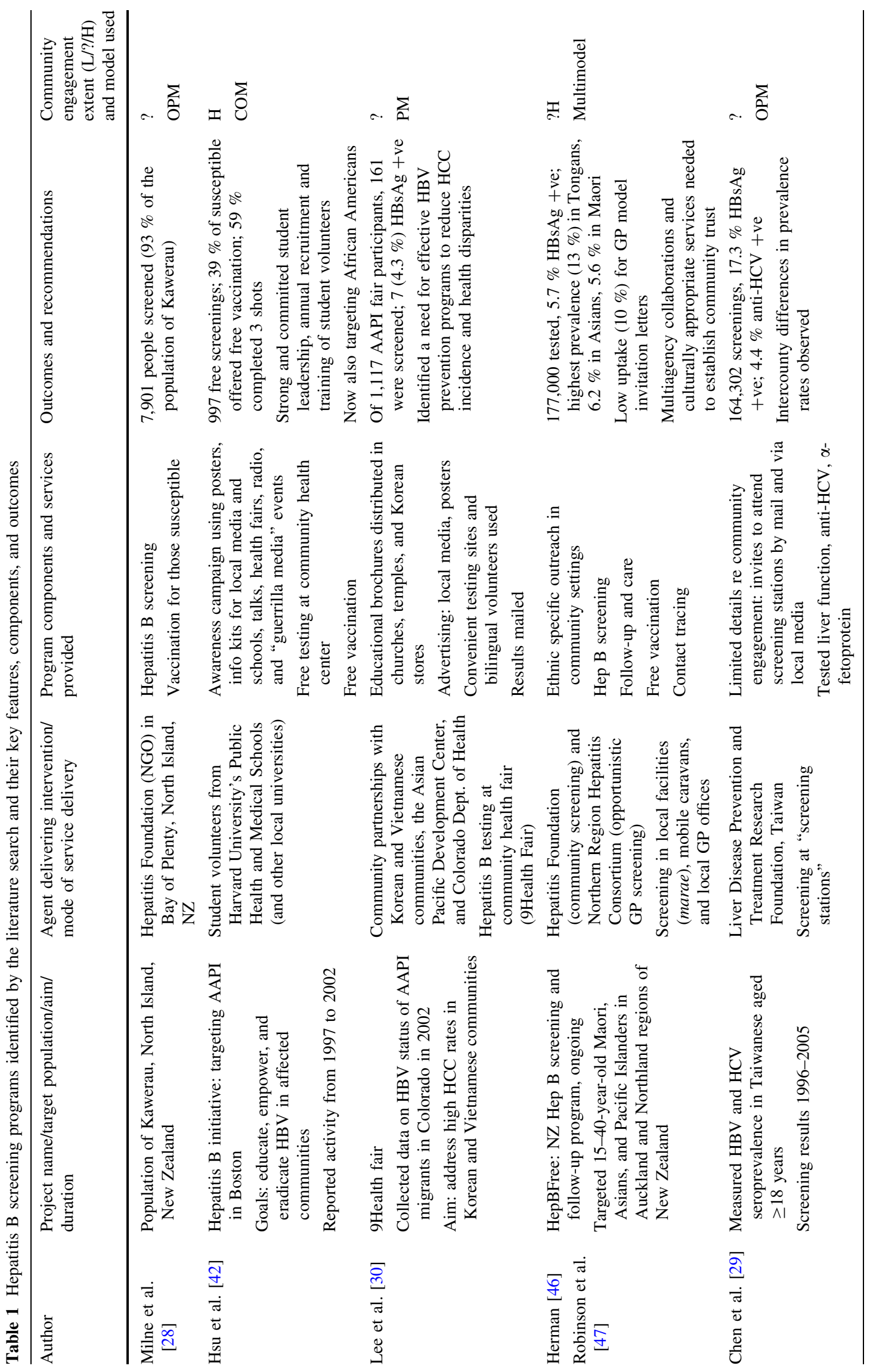




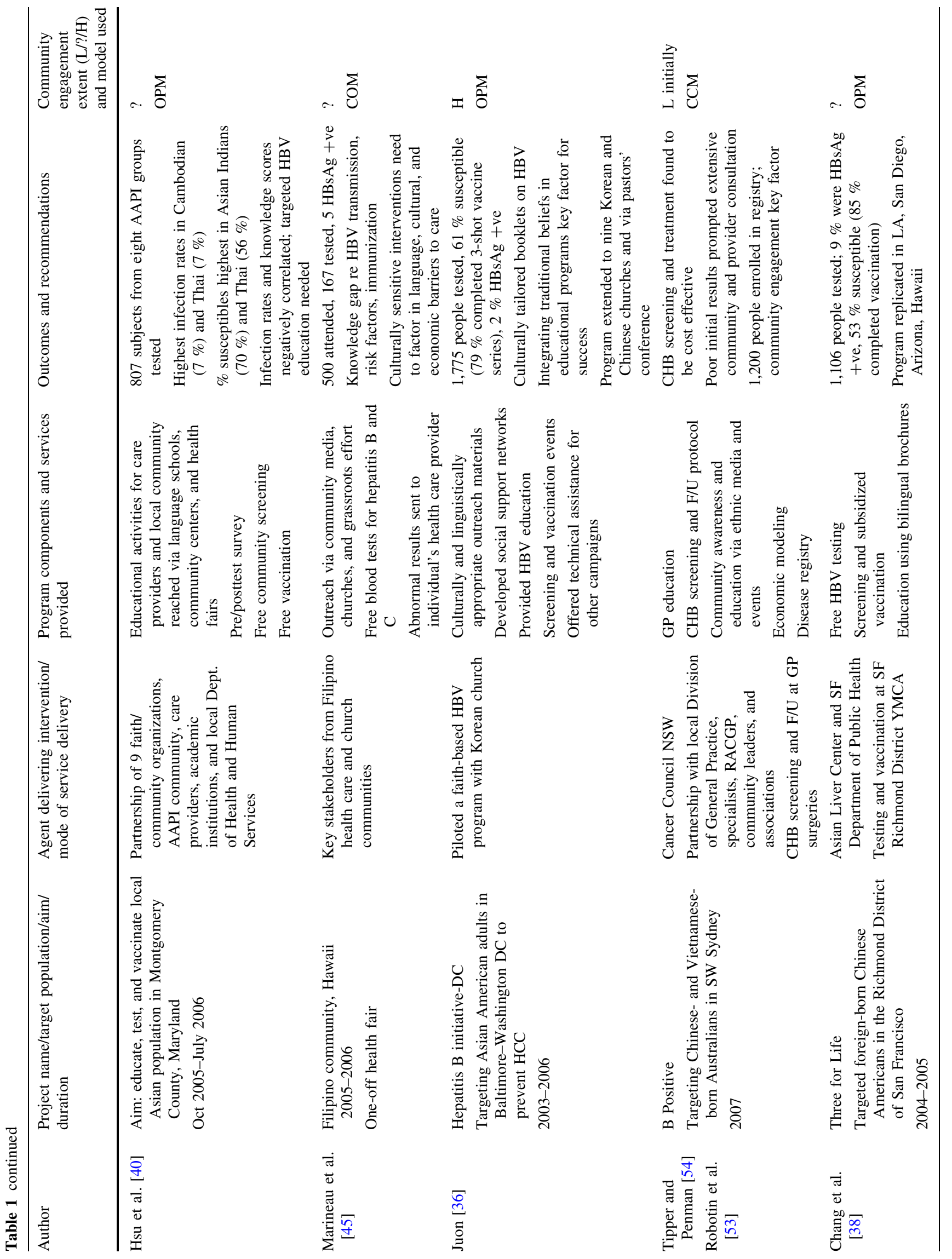




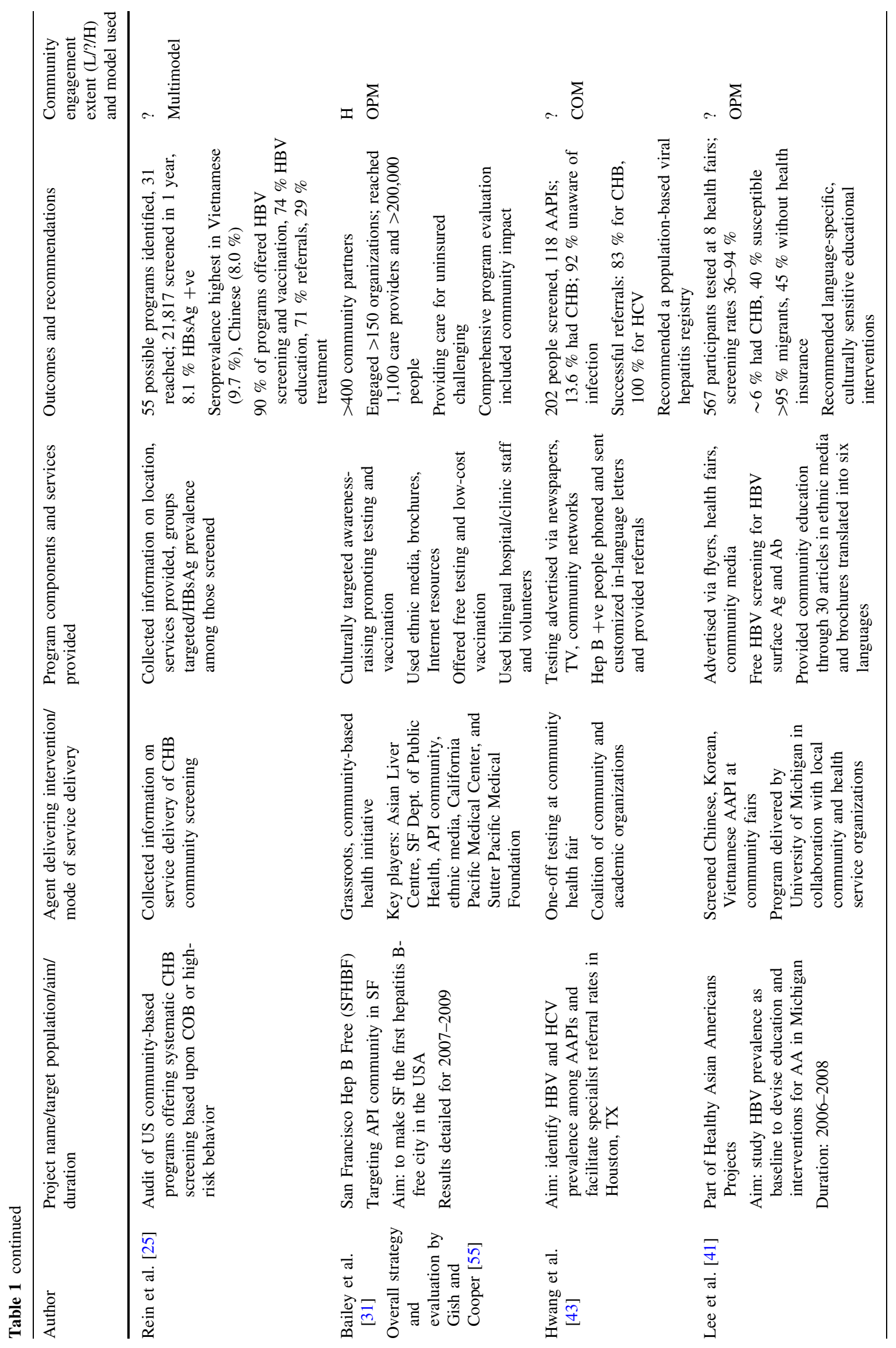




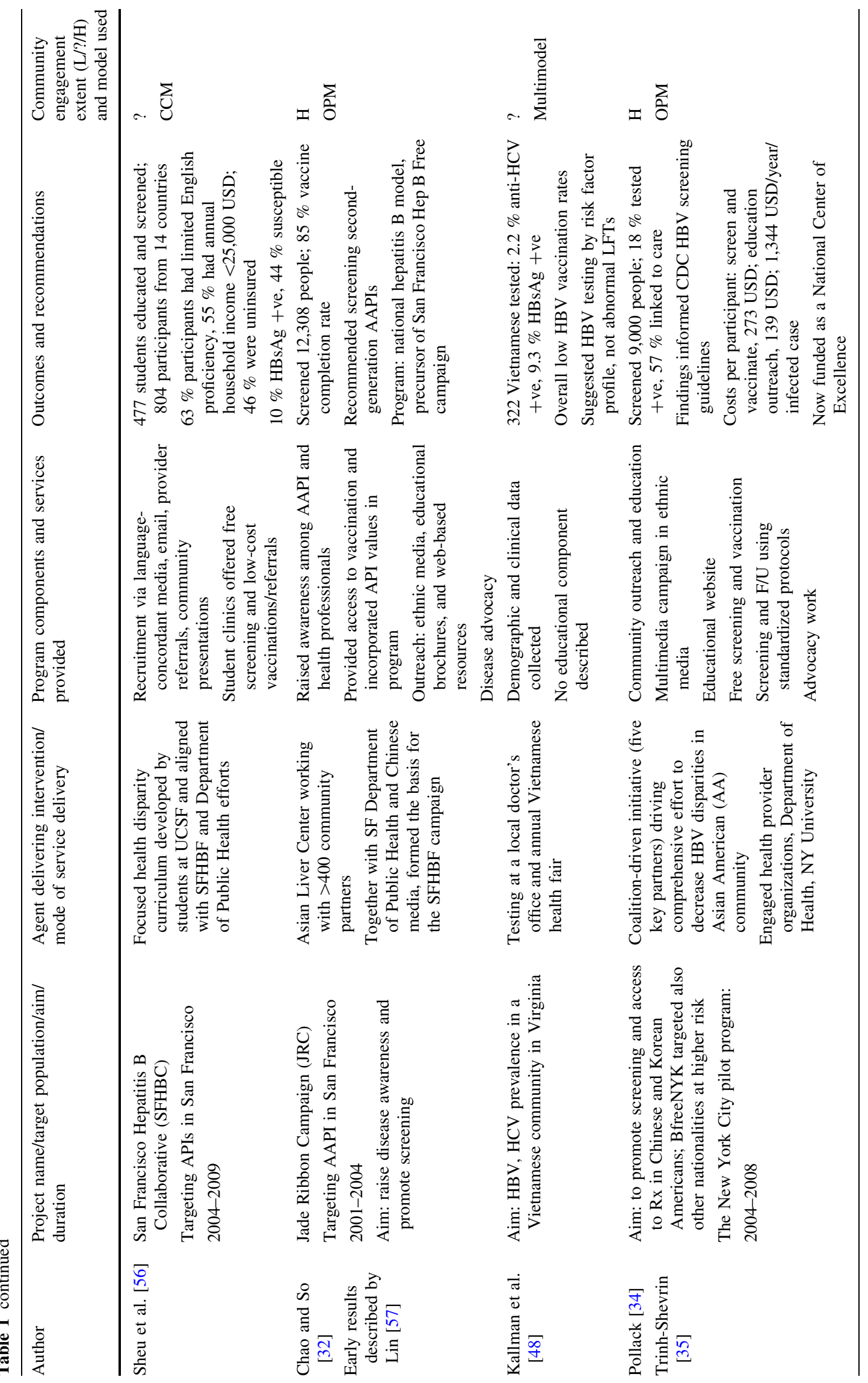




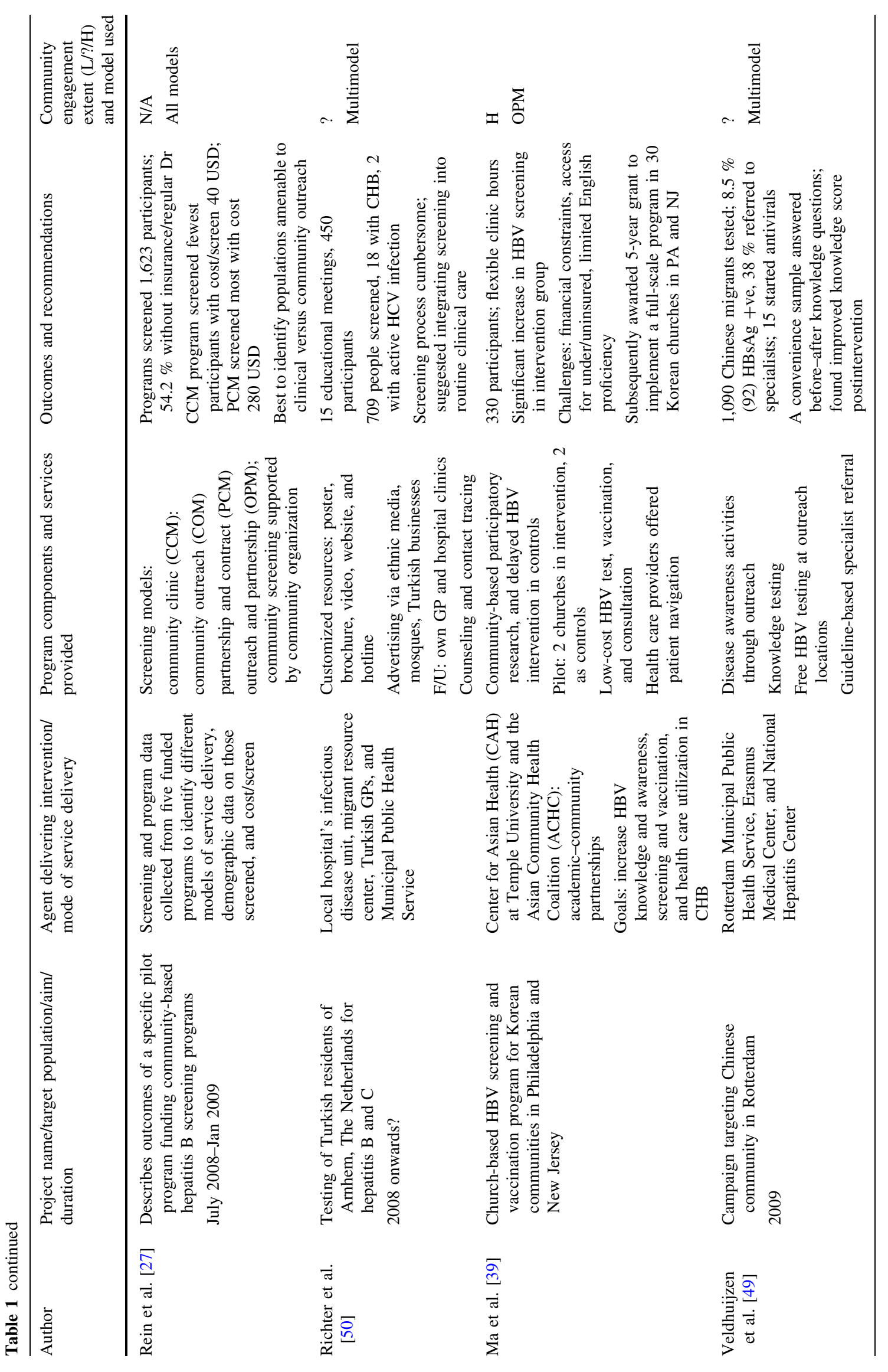




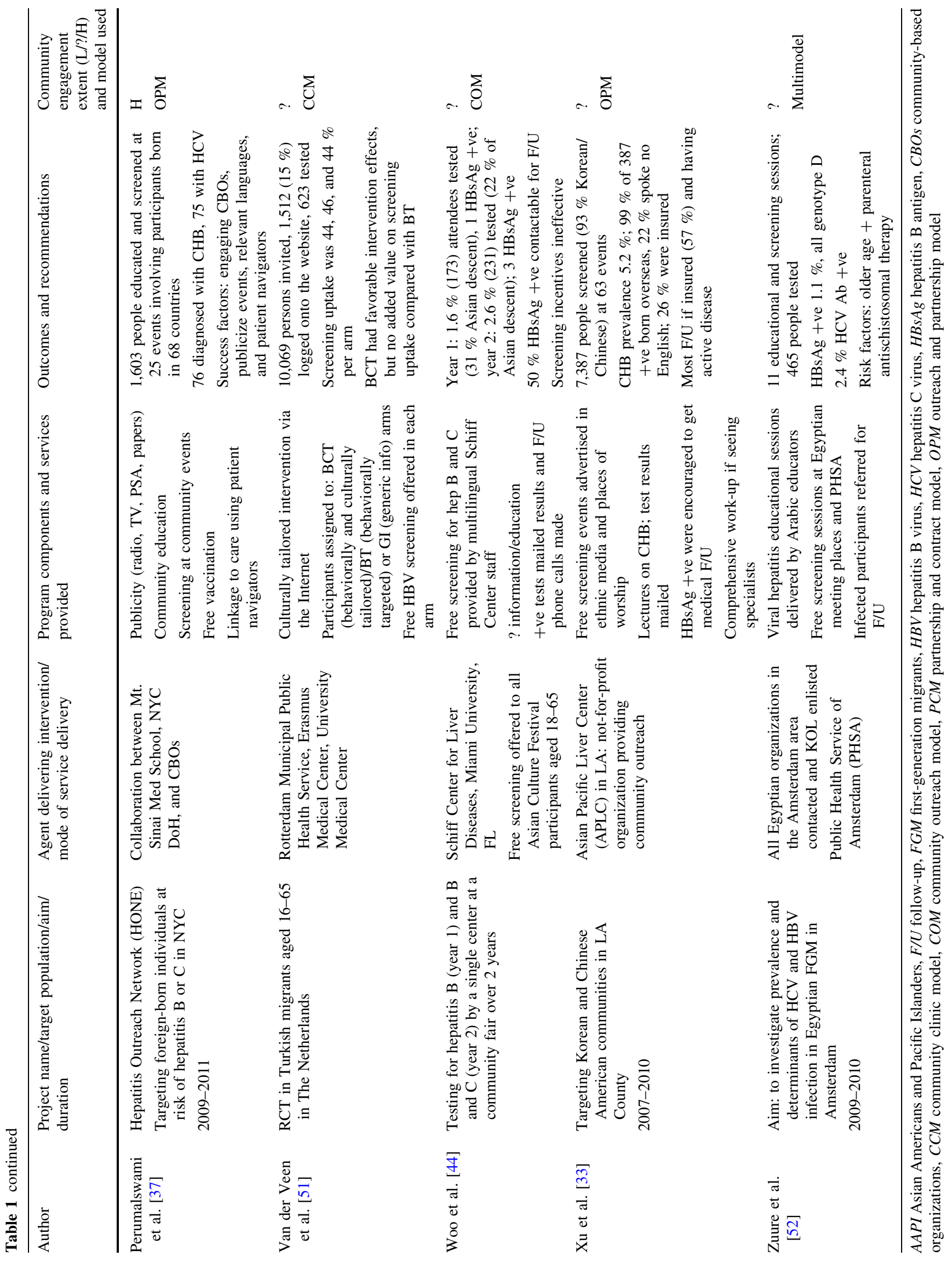


COMs provided screening through one-off events at community health fairs and/or community centers. All were US based and targeted Asian Americans and Pacific Islanders in Boston [42], Houston [43], Miami [44], and Hawaii [45]. No ongoing community engagement was documented, and they reached between 100 [45] and 1,000 people [42].

The HepBFree program in New Zealand used community screening with outreach in rural areas and screening in general practices (GPs) in Auckland [46, 47]; the latter was also employed by a program in Virginia, which combined testing at a local doctor's surgery with testing at an annual fair [48].

Multiple methods were employed by the Dutch initiatives: testing was offered in community centers, schools, churches, and the Municipal Public Health Service in Rotterdam and Arnhem [49, 50]; an Internet intervention was trialled in Rotterdam [51], and screening at Egyptian meeting places and the Public Health Service was offered in Amsterdam [52].

In San Francisco, clinic-based screening was offered by the Three for Life program [38] and through clinics run by medical students. The Australian program offers primary care-based screening by GPs in Sydney [53, 54].

Sufficient information allowed us to ascertain a high degree of community involvement in eight programs; the Australian B Positive program commenced as a clinical intervention delivered by general practitioners and was repositioned as a community-agency collaboration to increase program visibility and participation rates [53].

\section{Program target population}

The target populations ranged from country-wide hepatitis B and C screening in Taiwan [29] to city-wide screening in New York (BFreeNYC [34]) and San Francisco (Hep B Free) programs [31]. Screening targeted people of Asian and/or Pacific Islander heritage in Boston [42] and Maryland [39, 40] and the HONE program in New York [37]. The HepBFree program in New Zealand targeted the local Maori population, as well as Asian and Pacific Islander residents [46, 47]. Korean and Vietnamese Americans were the target population in Colorado [30], Korean and Chinese Americans in the Baltimore-Washington area, LA County, and San Francisco [31, 33], Chinese, Korean, and Vietnamese Americans in Michigan [41], the Filipino community in Hawaii [45], and Chinese-Korean communities in Philadelphia and New Jersey [39]. In Australia, the B Positive program targets Chinese and Vietnamese residents in Sydney [51], while Dutch programs targeted Chinese and Turkish migrant communities of Rotterdam and Arnhem [49-51], and Egyptian migrants in Amsterdam [52].
Some US-based programs were promoted and supported by faith-based organizations [36, 39, 40], and some were offered by clinical groups offering education and testing at community events [30, 43, 45]; while some screened all participants (in Miami, FL and Houston, TX) [43, 44], others based testing decision on risk factors (Colorado) [30].

In New Zealand, testing was offered at Maori meeting places (marae), mobile caravans, and through GP offices [46]. In Australia, it is offered through GP offices [54], and in The Netherlands at community sites and Municipal Public Health Services [49-52]. The Taiwanese program invited participants to attend clinics at designated screening stations [29].

\section{Program partners}

Most programs were the result of collaborations between academic institutions or clinics and community-based organizations; some also had support from local public health units. The number of community partners ranged from $>400$ in the case of San Francisco Hep B Free [32] to just the agency delivering the intervention [41, 44].

Study type

Two reports described controlled intervention studies: one was a church-based HBV screening and vaccination pilot program in Philadelphia [39], the other a randomized controlled trial (RCT) conducted in The Netherlands [51].

The US pilot study recruited 330 Korean Americans through churches in the intervention area, and randomized them to either HBV education and HBV testing at enrollment (the intervention group), or to a delayed intervention, where these services could be accessed at a later stage (the control group). A statistically significant increase in HBV screening was observed in the early intervention group compared with controls [39].

The Dutch study recruited first-generation Turkish residents of Rotterdam to a culturally tailored Internet-based intervention aiming to promote $\mathrm{HBV}$ screening [51]. Through a clustered randomized design, participants were computer-randomized to receive either a behavioral tailoring intervention (BT), one combining behavioral and cultural tailoring, or just generic online information. An invitation letter explained the intervention and directed recipients to the project's website, which "streamed" participants into one of the three intervention groups. Approximately $15 \%$ of those sent letters logged onto the website, and overall screening uptake was similar ( $\sim 5 \%$ ) across all three intervention groups [51]. This was the first documented intervention using the Internet to increase hepatitis B testing rates in a migrant community; 
given the low participation rate, these findings need further validation [51].

The remaining 25 papers describe nonrandomized screening interventions which incorporated some form of community outreach and education in addition to screening.

Program components and services provided

Programs publicized hepatitis B screening using ethnic media and flyers/posters; all but $3(88 \%)$ offered community education using lectures and workshops, educational brochures, articles published in ethnic newspapers, and web-based resources. City-wide programs in San Francisco and New York had sophisticated multimedia campaigns and marketing strategies and developed program-specific websites with tailored educational information.

Vaccination (either free of charge or subsidized) was offered by 12 programs (48\%); most US programs and the New Zealand programs offered it. Vaccination was not included in the Dutch, Taiwanese, and Australian programs, which may be due to the ability to access vaccination through other means.

One-year follow-up was provided by the two controlled intervention studies, with the San Francisco Hep B Free [55] and the BFreeNYC [34] programs also providing follow-up, constrained by limited resources. Long-term follow-up is offered by the New Zealand [47] and Australian programs [54].

The Dutch [49-52], Australian [54], and New Zealand programs [46] as well as some US programs offered linkage to care $[35,43,56]$ or employed a patient navigator to negotiate the medical system on the patients' behalf [41, 57]. Programs in Michigan [41], Texas [43], Virginia [48], Florida [44], and Southern California offered referrals to insured participants [33]; $71 \%$ of the US programs identified by Rein et al. [25] provided treatment referrals, with $29 \%$ providing antiviral treatment.

A complete CHB care package encompassing hepatitis B screening, HCC surveillance, ongoing disease monitoring, and treatment was offered by BFreeNYC [34] and San Francisco Hepatitis B Free [55] and programs in New Zealand [46, 47], Australia [54], and The Netherlands [49].

Some programs provided hepatitis C testing $[29,37,43$, $45,50,52]$, contact tracing (the New Zealand program) [45] or physician education about HBV (some US and the Australian program) $[32,34,54]$ or disease advocacy.

San Francisco seeks to become the first HBV-free city, with the Hep B Free Campaign offering screening, vaccination, and treatment to all Asian and Pacific Islander residents (representing $30 \%$ of its population) [10]. To improve disease surveillance, the city established a population-based chronic hepatitis B registry, with enhanced disease surveillance ascertaining transmission patterns and participants' ability to access hepatitis care [58]. The Australian program includes a CHB disease registry to optimize patient follow-up and collect population-level data on CHB disease characteristics [53, 54].

Program outcomes

Most interventions reported results in terms of the number of people reached, number of screenings performed, and estimated HBsAg prevalence overall and by ethnic groups.

The most comprehensive outcome measures were documented by the BFreeNYC program, which also conducted a random survey of Asian Americans 2 years after the program ended [34]. They documented a $34 \%$ increase in new CHB cases reported from areas with a high Asian population during its 4 years of activity, with $57 \%$ of people with CHB remaining in care until the end of the program [34]. BFreeNYC reached over 1 million people, provided education for 11,000 , screened approximately 9,000 people, and diagnosed and managed 6 cases of HCC and 22 of end-stage liver failure [34].

During its first 2 years, the San Francisco Hep B Free program reached over 200,000 people and tested 3,315 Asian-Pacific Islanders at standalone screening sites [31] and 12,000 people through the Jade Ribbon Campaign [32]; $6.5 \%$ were chronically infected and referred for follow-up care [31]. The largest "yield" of screening occurred in higher education establishments with a large proportion of Asian students, Asian street festivals and fairs [55].

The HepBFree New Zealand program tested 177,000 people, $5.7 \%$ being HBsAg-positive; significant regional and ethnic differences in $\mathrm{HBsAg}$-positive rates were observed among Maori (5.6 \%), Pacific islander (7.3\%), and Asian people (6.2\%) [47]. Successful outreach raised CHB community awareness and led to effective partnerships with local health care providers $[47,59]$.

With few exceptions, programs did not report the size of their target population, but the Kawerau study in New Zealand was able to test $93 \%$ of the town population, finding HBsAg prevalence rates of $4.2 \%$ among European residents and $18.2 \%$ amongst the Maori population [28].

Rein et al. [25] reported results for five US screening programs screening over 1,600 participants over 7 months; $95 \%$ of those screened were foreign-born, and most $(56 \%)$ did not have a regular medical practitioner or health insurance $(54 \%)$.

Screening uptake was highest for programs using an outreach and partnership model (OPM) [31, 33, 37, 59]; the $\mathrm{COM}$ at community fairs yielded fewer screenings [30, 34, 45]; screening offered by clinical experts had low uptake. 
Box 1 Factors ensuring effective program delivery

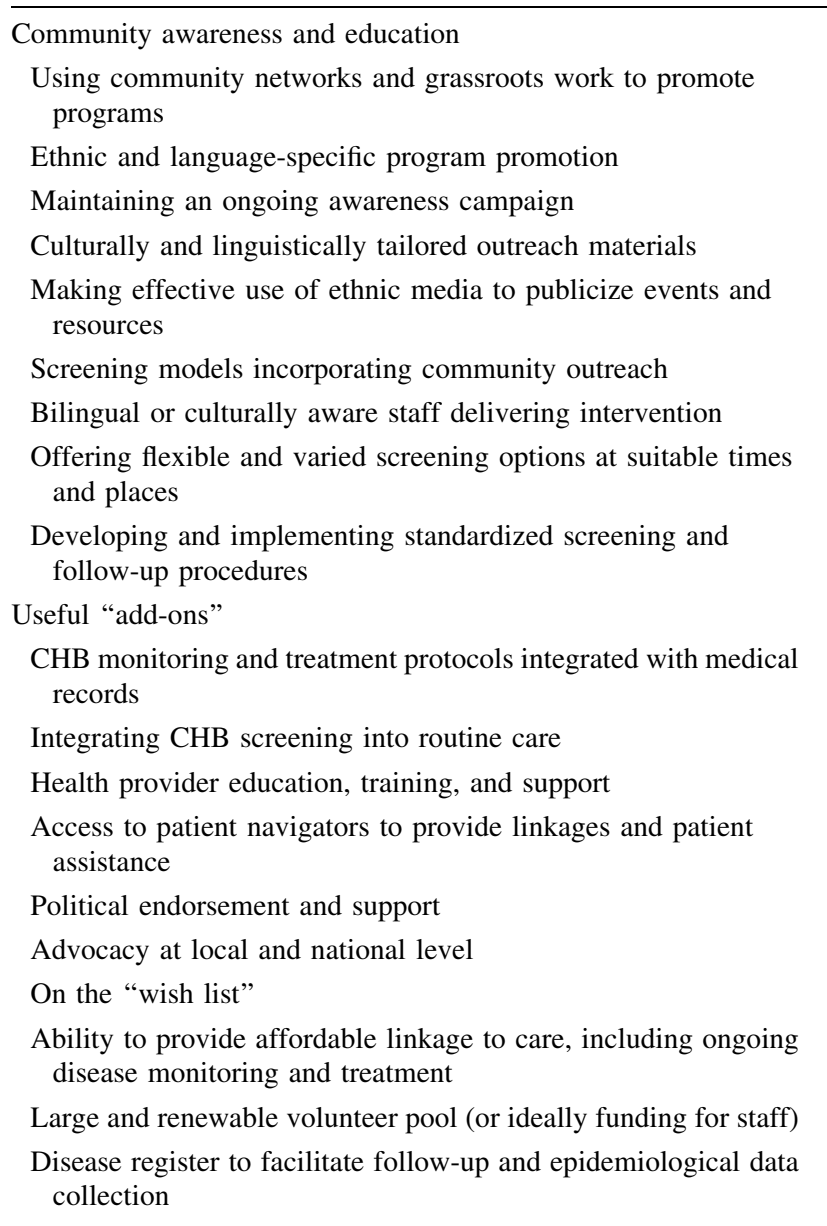

The Healthy Asian American Projects initiative in Michigan targeted Chinese, Korean, and Vietnamese Asian Americans at eight health fairs over 2 years; despite wide advertising, education, and distribution of brochures in six languages, screening rates remained low, attributed to "resistance by Asian Americans to participate in clinical studies" [41]. Similar outcomes were documented by a program in Florida, where free access to specialists and a screening incentive led to 1.6 and $2.6 \%$ of participants taking up screening in the first and second year, respectively [44].

Successful completion of hepatitis B vaccination was monitored by the Hepatitis B initiative in Boston (59\%) [40] and Washington (79 \%) [36], as well as the Three for Life (85\%) [37] and Jade Ribbon campaigns in San Francisco [32].

Linkage to care (beyond vaccination) was offered by 11 programs, mostly in countries with socialized medicine: in Europe 2 (or $66 \%$ ) out of 3 (or $66 \%$ ) and in AustraliaNew Zealand 2 (or $66 \%$ ) out of 3 (or $66 \%$ ) programs offered linkage to care, compared with the USA, where 6 (30\%) out of 20 did so. In five US screening programs,
$54 \%$ of participants had no insurance cover and/or no regular health care provider [25]; in Michigan $45 \%$ [41], in San Francisco $46 \%$ [31], and in Los Angeles $74 \%$ [33] of people accessing the programs were uninsured.

BFreeNYK was able to maintain $57 \%$ of its $1,100 \mathrm{CHB}$ patients in care until the end of the 4-year program [34], but high rates of loss to follow-up occurred in other programs: just $77 \%$ of the 7,000 people screened by the Asian Pacific Liver Center in Los Angeles could be traced 6 months later [33].

\section{Program costs}

Cost of care estimates were provided by the BFreeNYC program, with annual cost per infected patient estimated at 1,598 USD [34]. Rein et al. [27] compared the costs of four types of community screening in the USA and found that CCM was the least costly per screened participant, albeit screening fewer participants, while the partnership and contract model (PCM) screened most participants, at the highest cost per screening.

\section{Discussion}

Over the last 30 years, many initiatives have sought to increase hepatitis B screening rates in high-risk communities, by targeting migrant populations in the USA, Australia, and The Netherlands, as well as indigent populations in New Zealand and Taiwan. A few programs successfully reached large numbers of people, but the majority screened modest numbers: the 31 programs active across the USA in 2008 screened a total of 21,817 people, or approximately 700 people per program. Even assuming seroprevalence rates of $10 \%$ in the target populations, this translates into just 2,000 new CHB diagnoses. Given that the USA has approximately 2 million infected people [60], of whom $60 \%$ (i.e., 1.2 million) are unaware of their infection [19], opportunistic screening cannot make a significant impact in populations with low access to medical care [19], making community-based screening a more attractive option. Successful programs achieved significant buy-in from target communities, delivering culturally appropriate educational initiatives and offering comprehensive care packages, as exemplified by the BFreeNYC [34], San Francisco Hep B Free [55], and the New Zealand [46, 47] and Australian programs [53, 54].

Large US programs grappled with the challenge of offering ongoing care to uninsured participants, as twothirds of people not attending follow-up arrangements had no financial means or medical insurance [33]. The BFreeNYC program was the only US program able to provide 
free treatment over its 4-year existence [34]; the San Francisco programs faced great logistical challenges to provide access to care to uninsured [32]. Availability of free medical care did not ensure successful referral to care: one-third of patients eligible for treatment in a Dutch study did not see a specialist [61], and the uptake of the Sydneybased program was low initially, despite providing free screening and treatment [50].

Successful programs found innovative ways to leverage organizational and individual resources, including garnering political and practical support [34, 62]. To ensure program sustainability, costs and outcomes require close scrutiny; while $\mathrm{CHB}$ screening integrated with primary care services is less labor intensive and less costly, evidence from the USA [27] and New Zealand [47] suggests it delivers lower screening rates. Conversely, outreach models deliver greater community involvement, but at higher costs. The New York program suggested main-streaming these activities into primary care and educating primary care providers [34].

Key program challenges included the high cost of screening and limited ability to offer affordable long-term care, so new approaches and financing arrangements are critical to make access to care a reality for many. Most US programs relied upon volunteer support and commitment from communsity-based organizations, and reliance on their continued support may be unsustainable in the long run $[34,55]$. Given that low community awareness, widespread misinformation, and persisting cultural stigma remain significant barriers, sustained community awareness-raising campaigns, complemented by culturally appropriate care delivery models, are acutely needed [24].

The noted "resistance by Asian Americans to participate in clinical studies" [41] prompted recommendations for educational interventions to be developed in native Asian languages, rather than using translated English resources [41]. Although previous research suggested that Asian Americans prefer to access health information from health care providers speaking their language [63], programs providing access to health specialists speaking Asian languages and offering screening incentives did not achieve a great deal of success [34].

The linkage to care and treatment is critical to ensure program buy-in and effectiveness, and this poses serious challenges in many countries with high $\mathrm{CHB}$ disease prevalence, but with costs of antiviral therapies likely to fall in the future, a community-based model of $\mathrm{CHB}$ diagnosis could still provide the impetus for offering a large-scale treatment program for a larger population.

Box 1 provides some summary points of critical success factors and program limitations and challenges.

\section{Conclusions}

This review suggests that community-based hepatitis B screening is an active area of research and experimentation in countries with large migrant populations, such as the USA, The Netherlands, New Zealand, and Australia. Successful programs used a range of strategies to increase community awareness and knowledge and leveraged community partnerships to achieve significant community engagement and penetration. They combined HBV education, community empowerment, and collaborative partnerships, and they incorporated the target population's values in program design and implementation. In addition to screening and vaccination, "ideal" programs must offer access to ongoing care and support, inclusive of antiviral therapy and HCC screening.

Many unanswered questions still remain regarding optimal funding mechanisms, program sustainability, the best way of ensuring linkage to care, and how to develop, select, and implement the most effective strategies of screening, disease surveillance, and community engagement and education.

Acknowledgments J.G. is funded by the Sydney Medical Foundation of the University of Sydney and by grants from the National Health and Medical Research Council of Australia (project grant 1047417 and programme grant 1053206), the Cancer Council New South Wales (Strategic Research Partnership grant SRP 08-03), and the New South Wales Cancer Institute (grant 11/TRC/1-6).

Compliance with ethical requirements statement Ethics approval for the B Positive program has been granted by the South West Sydney Area Health Service. This paper is the result of desktop research, as we conducted a review of the published evidence of existing programs.

Open Access This article is distributed under the terms of the Creative Commons Attribution License which permits any use, distribution, and reproduction in any medium, provided the original author(s) and the source are credited.

\section{References}

1. Custer B, Sullivan SD, Hazlet TK, Iloeje U, Veenstra DL, Kowdley KV. Global epidemiology of hepatitis B virus. J Clin Gastroenterol. 2004;38(10 Suppl 3):S158-S168

2. San Francisco Department of Public Health. Chronic Viral Hepatitis Registry Project. Chronic Hepatitis B Surveillance Report 2007-2008. San Francisco Department of Public Health, 2009:12

3. World Health Organization (WHO). Immunization Surveillance, Assessment and Monitoring. Geneva: WHO; 2014.

4. Lozano R, Naghavi M, Foreman K, Lim S, Shibuya K, Aboyans $\mathrm{V}$, et al. Global and regional mortality from 235 causes of death for 20 age groups in 1990 and 2010: a systematic analysis for the Global Burden of Disease Study 2010. Lancet. 2012;380(9859):2095-2128 
5. El-Serag HB. Epidemiology of viral hepatitis and hepatocellular carcinoma. Gastroenterology 2012;142(6):1264 e1-1273 e1

6. Haworth EA, Soni Raleigh V, Balarajan R. Cirrhosis and primary liver cancer amongst first generation migrants in England and Wales. Ethn Health. 1999;4(1-2):93-99

7. Visser $\mathrm{O}$, van Leeuwen FE. Cancer risk in first generation migrants in North-Holland/Flevoland, The Netherlands, 1995-2004. Eur J Cancer. 2007;43(5):901-908

8. Supramaniam R, O’Connell DL, Tracey E, Sitas F. Cancer Incidence in New South Wales Migrants 1991-2001. Sydney: The Cancer Council NSW; 2006

9. McDermott S, Desmeules M, Lewis R, Gold J, Payne J, Lafrance $\mathrm{B}$, et al. Cancer incidence among Canadian immigrants, 1980-1998: results from a national cohort study. J Immigr Minor Health. 2011;13(1):15-26

10. McBride G. Hepatitis B virus-induced liver cancer in Asian Americans: a preventable disease. J Natl Cancer Inst. 2008;100(8) :528-529

11. Liaw Y-F, Sung JJY, Chow WC, Farrell G, Lee C-Z, Yuen H, et al. Lamivudine for patients with chronic hepatitis $B$ and advanced liver disease. N Engl J Med. 2004;351(15):1521-1531

12. Chang TT, Gish RG, de Man R, Gadano A, Sollano J, Chao YC, et al. A comparison of entecavir and lamivudine for $\mathrm{HBeAg-positive}$ chronic hepatitis B. N Engl J Med. 2006;354(10):1001-1010

13. Chang TT, Liaw YF, Wu SS, Schiff E, Han KH, Lai CL, et al. Long-term entecavir therapy results in the reversal of fibrosis/ cirrhosis and continued histological improvement in patients with chronic hepatitis B. Hepatology. 2010;52(3):886-893

14. Papatheodoridis GV, Lampertico P, Manolakopoulos S, Lok A. Incidence of hepatocellular carcinoma in chronic hepatitis B patients receiving nucleos(t)ide therapy: a systematic review. J Hepatol. 2010;53(2):348-356

15. Hutton DW, Tan D, So SK, Brandeau ML. Cost-effectiveness of screening and vaccinating Asian and Pacific Islander adults for hepatitis B. Ann Intern Med. 2007;147(7):460-469

16. Wong WW, Woo G, Jenny Heathcote E, Krahn M. Cost effectiveness of screening immigrants for hepatitis B. Liver Int. 2011;31(8):1179-1190

17. Robotin MC, Kansil M, Howard K, George J, Tipper S, Dore GJ, et al. Antiviral therapy for hepatitis B-related liver cancer prevention is more cost-effective than cancer screening. J Hepatol. 2009;50(5):990-998

18. Veldhuijzen IK, Toy M, Hahne SJ, De Wit GA, Schalm SW, de Man RA, et al. Screening and early treatment of migrants for chronic hepatitis B virus infection is cost-effective. Gastroenterology. 2010;138(2):522-530

19. IOM (Institute of Medicine). Hepatitis and Liver Cancer: A National Strategy for Prevention and Control of Hepatitis B and C. Washington DC: Institute of Medicine; 2010

20. Cowie B, Kelly H. Outcomes of a complex dynamic mathematical model of hepatitis B virus in Australia. Hepatol Int. 2010;27:59

21. Hatzakis A, Wait S, Bruix J, Buti M, Carballo M, Cavaleri M, et al. The state of hepatitis B and C in Europe: report from the hepatitis $\mathrm{B}$ and $\mathrm{C}$ summit conference. J Viral Hepat. 2011;18(Suppl 1):1-16

22. Ganem D, Prince AM. Hepatitis B virus infection-natural history and clinical consequences. N Engl J Med. 2004;350(11): $1118-1129$

23. Status of Vietnamese Health: Santa Clara County, California, 2011. Santa Clara Public Health Department 2011. http://www. sccgov.org/sites/sccphd/en-us/Partners/Data/Documents/VHA\% 20Full\%20Report,\%202011.pdf

24. Hu KQ, Pan CQ, Goodwin D. Barriers to screening for hepatitis B virus infection in Asian Americans. Dig Dis Sci. 2011;56(11): 3163-3171
25. Rein DB, Lesesne SB, Leese PJ, Weinbaum CM. Communitybased hepatitis B screening programs in the United States in 2008. J Viral Hepat. 2010;17(1):28-33

26. Whitehead T. Community based interventions, definitions and types. The Cultural Ecology of Health and Change (CEHC). University of Maryland; 2002

27. Rein DB, Lesesne SB, Smith BD, Weinbaum CM. Models of community-based hepatitis B surface antigen screening programs in the U.S. and their estimated outcomes and costs. Public Health Rep. 2011;126(4):560-567

28. Milne A, Allwood GK, Moyes CD, Pearce NE, Lucas CR. Prevalence of hepatitis B infections in a multiracial New Zealand community. N Z Med J. 1985;98(782):529-532

29. Chen CH, Yang PM, Huang GT, Lee HS, Sung JL, Sheu JC. Estimation of seroprevalence of hepatitis B virus and hepatitis $\mathrm{C}$ virus in Taiwan from a large-scale survey of free hepatitis screening participants. J Formos Med Assoc. 2007;106(2):148-155

30. Lee H, Hontz I, Warner A, Park SJ. Hepatitis B infection among Asian American Pacific Islanders in the Rocky Mountain area. Appl Nurs Res. 2005;18(1):2-6

31. Bailey MB, Shiau R, Zola J, Fernyak SE, Fang T, So SK, et al. San Francisco Hep B Free: A Grassroots Community Coalition to Prevent Hepatitis B and Liver Cancer. J Commun Health 2010. http://www.ncbi.nlm.nih.gov/pubmed/21125320

32. Chao S, So S. The Jade Ribbon Campaign: a systematic, evidence-based public awareness campaign to improve Asian and Pacific Islander health. J Commun Healthc. 2011;4(1):46-55

33. Xu JJ, Tien C, Chang M, Rhee J, Tien A, Bae HS, et al. Demographic and serological characteristics of Asian Americans with hepatitis B infection diagnosed at community screenings. J Viral Hepat. 2013;20(8):575-581

34. Pollack H, Wang S, Wyatt L, Peng CH, Wan K, Trinh-Shevrin C, et al. A comprehensive screening and treatment model for reducing disparities in hepatitis B. Health Aff (Millwood) 2011;30(10):1974-1983

35. Trinh-Shevrin C, Pollack HJ, Tsang T, Park J, Ramos MR, Islam $\mathrm{N}$, et al. The Asian American hepatitis B program: building a coalition to address hepatitis B health disparities. Prog Community Health Partnersh 2011;5(3):261-271

36. Juon HS, Strong C, Oh TH, Castillo T, Tsai G, Oh LD. Public health model for prevention of liver cancer among Asian Americans. J Community Health 2008;33(4):199-205

37. Perumalswami PV, Factor SH, Kapelusznik L, Friedman SL, Pan CQ, Chang C, et al. Hepatitis Outreach Network: a practical strategy for hepatitis screening with linkage to care in foreignborn communities. J Hepatol. 2013;58(5):890-897

38. Chang ET, Sue E, Zola J, So SK. 3 For Life: a model pilot program to prevent hepatitis B virus infection and liver cancer in Asian and Pacific Islander Americans. Am J Health Promot. 2009;23(3):176-181

39. Ma GX, Gao W, Tan Y, Chae WG, Rhee J. A community-based participatory approach to a hepatitis B intervention for Korean Americans. Prog Community Health Partnersh. 2012;6(1):7-16

40. Hsu CE, Liu LC, Juon HS, Chiu YW, Bawa J, Tillman U, et al. Reducing liver cancer disparities: a community-based hepatitis-B prevention program for Asian-American communities. J Natl Med Assoc. 2007;99(8):900-907

41. Lee J, Lok AS, Chen J. Hepatitis B prevalence among Asian Americans in Michigan: an assessment to guide future education and intervention strategies. J Community Health. 2010;35(5) :534-542

42. Hsu L, DeJong W, Hsia R, Chang M, Ryou M, Yeh E. Student leadership in public health advocacy: lessons learned from the Hepatitis B Initiative. Am J Public Health. 2003;93(8):1250-1252

43. Hwang JP, Mohseni M, Gor BJ, Wen S, Guerrero H, Vierling JM. Hepatitis B and hepatitis C prevalence and treatment referral 
among Asian Americans undergoing community-based hepatitis screening. Am J Public Health. 2010;100(Suppl 1):S118-S124

44. Woo C, Hill M, de Medina M, Schiff E. Screening for hepatitis B virus and hepatitis $\mathrm{C}$ virus at a community fair: a single-center experience. Gastroenterol Hepatol. 2013;9(5):293-299

45. Marineau M, Tice AD, Taylor-Garcia D, Akinaka KT, Lusk H, Ona F. Culturally sensitive strategies designed to target the silent epidemic of hepatitis B in a Filipino community. Hawaii Med J. 2007;66(6):154-156

46. Herman A, Bullen C, Finau S, Ofanoa M. Mobilising Pacific people for health: insights from a hepatitis B screening programme in Auckland, New Zealand. Pac Health Dialog. 2006;13(2):9-15

47. Robinson T, Bullen C, Humphries W, Hornell J, Moyes C. The New Zealand Hepatitis B Screening Programme: screening coverage and prevalence of chronic hepatitis B infection. N Z Med J. 2005;118(1211):U1345

48. Kallman JB, Tran S, Arsalla A, Haddad D, Stepanova M, Fang Y, et al. Vietnamese community screening for hepatitis B virus and hepatitis C virus. J Viral Hepat. 2011;18(1):70-76.

49. Veldhuijzen IK, Wolter R, Rijckborst V, Mostert M, Voeten HA, Cheung Y, et al. Identification and treatment of chronic hepatitis $\mathrm{B}$ in Chinese migrants: results of a project offering on-site testing in Rotterdam, the Netherlands. J Hepatol. 2012;57(6):1171-1176

50. Richter C, Beest GT, Sancak I, Aydinly R, Bulbul K, LaetemiaTomata F, et al. Hepatitis B prevalence in the Turkish population of Arnhem: implications for national screening policy? Epidemiol Infect. 2012;140(4):724-730

51. van der Veen YJ, van Empelen P, de Zwart O, Visser H, Mackenbach JP, Richardus J. Cultural tailoring to promote hepatitis B screening in Turkish Dutch: a randomized control study. Health Promot Int. 2013;52:8950-8961

52. Zuure FR, Bouman J, Martens M, Vanhommerig JW, Urbanus AT, Davidovich U, et al. Screening for hepatitis B and C in firstgeneration Egyptian migrants living in the Netherlands. Liver Int. 2013;33(5):727-738

53. Robotin M, Porwal M, Kansil M, Penman A, George J. Community-based prevention of hepatitis-B-related liver cancer:
Australian insights. Bull World Health Organ. 2014;92(5): 374-379

54. Tipper S, Penman AG. The NSW HBV and liver cancer pilot program: an update on the 'B Positive' Project. Cancer Forum. 2009;33(2):129-133

55. Gish RG, Cooper SL. Hepatitis B in the Greater San Francisco Bay Area: an integrated programme to respond to a diverse local epidemic. J Viral Hepat. 2010;17(1):28-33

56. Sheu LC, Toy BC, Kwahk E, Yu A, Adler J, Lai CJ. A model for interprofessional health disparities education: student-led curriculum on chronic hepatitis B infection. J General Intern Med. 2010;25(2):140-145

57. Lin SY, Chang ET, So SK. Why we should routinely screen Asian American adults for hepatitis B: a cross-sectional study of Asians in California. Hepatology. 2007;46(4):1034-1040

58. Chronic Hepatitis B Surveillance Report 2007-2008, San Francisco. Chronic viral hepatitis Registry project San Francisco: Communicable Disease Control and Prevention Section, San Francisco 2009

59. van der Veen YJ, de Zwart O, Mackenbach J, Richardus JH. Cultural tailoring for the promotion of hepatitis B screening in Turkish Dutch: a protocol for a randomized controlled trial. BMC Public Health. 2010;10:674

60. Kowdley KV, Wang CC, Welch S, Roberts H, Brosgart CL. Prevalence of chronic hepatitis B among foreign-born persons living in the United States by country of origin. Hepatology. 2012;56(2):422-433

61. Mostert MC, Richardus JH, de Man RA. Referral of chronic hepatitis B patients from primary to specialist care: making a simple guideline work. J Hepatol. 2004;41(6):1026-1030

62. Chao SD, Chang ET, Le PV, Prapong W, Kiernan M, So SK. The Jade Ribbon Campaign: a model program for community outreach and education to prevent liver cancer in Asian Americans. J Immigr Minor Health. 2009;11(4):281-290

63. Chen CJ, Kendall J, Shyu YI. Grabbing the rice straw: health information seeking in Chinese immigrants in the United States. Clin Nurs Res. 2010;19(4):335-353 